\title{
Physiologically Based Pharmacokinetic Modeling of Benzene Metabolism in Mice through Extrapolation from in Vitro to in Vivo
}

\author{
Cammey E. Cole ${ }^{1,2,3}$, Hien T. Tran ${ }^{1,2}$, and Paul M. Schlosser ${ }^{1,3}$ \\ ${ }^{1}$ Center for Research in Scientific Computation, North Carolina State University, Raleigh, North Carolina \\ 2 Department of Mathematics, North Carolina State University, Raleigh, North Carolina \\ ${ }^{3}$ Chemical Industry Institute of Toxicology, Research Triangle Park, North Carolina
}

\begin{abstract}
Benzene $\left(\mathrm{C}_{6} \mathrm{H}_{6}\right)$ is a highly flammable, colorless liquid. Ubiquitous exposures result from its presence in gasoline vapors, cigarette smoke, and industrial processes. Benzene causes leukemia in humans when they are exposed to high doses for extended periods; however, leukemia risks in humans at low exposures are uncertain. The exposure-dose-response relationship of benzene in humans is expected to be nonlinear because exposure typically occurs by inhalation. After inhalation, benzene undergoes a series of metabolic transformations, detoxifying and activating, in the liver resulting in multiple metabolites that exert toxic effects on the bone marrow. We developed a physiologically based pharmacokinetic model for the uptake and elimination of benzene in mice to relate the concentration of inhaled and orally administered benzene to the tissue doses of benzene and its key metabolites, benzene oxide, phenol, and hydroquinone. As many parameters as possible were taken from the literature; in particular, metabolic parameters obtained from in vitro studies with mouse liver were used since comparable parameters are also available for humans. Unknown parameters were estimated by fitting the model to published data. The model was constrained by using the in vitro metabolic parameters, and data from multiple laboratories and experiments were used. Despite these constraints and sources of variability, the model simulations matched the data reasonably well in most cases, showing that in vitro metabolic constants can be successfully extrapolated to predict in vivo data for benzene metabolism and dosimetry. Therefore in vitro metabolic constants for humans can subsequently be extrapolated to predict the dosimetry of benzene and its metabolites in humans; this will allow us to better estimate the risks of low-level benzene exposures.
\end{abstract}




\section{INTRODUCTION}

Benzene is an ubiquitous environmental pollutant and is a component of both cigarette smoke and automobile emissions (Wallace, 1990; Yardley-Jones et al., 1991). It has also been a widely used solvent and a precursor for many synthetic materials (Legathe et al., 1994). Chronic exposures to benzene result in a variety of blood and bone marrow disorders in both humans and laboratory animals (Kalf, 1987; MacEachern et al., 1992). Increased incidence of acute myelogenous leukemia in humans resulted from high-level benzene exposures. Although the leukemogenicity of benzene has not been proven in rats or mice, benzene has been demonstrated to induce solid tumors in those species (Maltoni, 1983, 1985).

Mice lacking a functional gene for the enzyme cytochrome P450 2E1 (CYP2E1) do not suffer the hematotoxic and genotoxic effects that benzene causes in normal mice expressing functional CYP2E1 (Valentine et al., 1996). Most metabolism of benzene occurs in the liver, and enzymes capable of metabolism are also present in the lungs and kidneys of rodents and in the bone marrow of some rodent species (Andrews et al., 1979; Chaney and Carlson, 1995). The initial metabolite of benzene is benzene oxide. Benzene oxide rearranges spontaneously to form phenol. Phenol is subsequently hydroxylated to form hydroquinone and catechol as well as 1,2,4-benzenetriol (Lindstrom et al., 1997; Yardley-Jones et al., 1991). Benzene is initially oxidized by cytochrome P450 (CYP) enzymes; these enzymes also catalyze the hydroxylation of the phenolic derivatives (Snyder et al., 1993; Valentine et al., 1996).

Benzene exposure has long been a health concern for humans. During World War II, workers who were exposed to benzene exhibited signs of vitamin C deficiency (Parke, 1996). In a nationwide investigation of benzene poisoning in China from 1972 to 1987 , workers in small factories, especially in shoe manufacturing, had an incidence of aplastic anemia 5.8 times higher than the general population; the exposures levels were estimated to be between 50 and 350 ppm (Smith, 1996).

In the late 1980s, a study was done in which workers in Japan and China received urine tests at the end of the work week; those who had been exposed to benzene had higher concentrations of benzene metabolites in their urine than those workers who had not been exposed (Inoue et al., 1988). In recent studies conducted in China, some groups of people appeared to be more susceptible to benzene exposure than others. Human subjects who had certain allele mutations, such as having both a rapid excretion of chlorzoxazone (indicative of high CYP2E1 activity) and two copies of the $N Q O 1{ }^{609} \mathrm{C} \rightarrow T$, were more susceptible to benzene-related disease than subjects with slow excretion of chlorzoxazone who carried one or two wild-type NQO1 alleles (Rothman et al., 1997). These studies show that individual factors affect exposure responses and risks in humans.

Much work has been done through the years on benzene dosimetry in rodents. Physiologically based pharmacokinetic (PBPK) modeling seeks to incorporate known physiological parameters such as body weight, organ volumes, and blood flow rates in particular tissues as well as known partition coefficients that have been obtained through experimentation. This model also represents uptake and metabolism by considering the chemical and physical processes that are occurring in the body. The objective of this study was to develop a PBPK model that predicts tissue 
concentrations of certain metabolites in mice based on exposure using metabolic parameters obtained in vitro. Since in vitro metabolic parameters are also available for humans, the model could then be extrapolated to humans for risk assessment.

\section{METHODS}

The structure of the PBPK model used in this study is depicted in Figure 1. To the extent possible, metabolic parameters have been estimated from previously published in vitro work. Our model uses these parameters while scaling them by the protein concentrations in liver to model in vivo metabolism. Physiological parameters, specifically tissue volumes and blood flows, were also taken from the open literature. In addition, a list of abbreviations and symbols used in the model can be found in Appendix A.

\section{Model Structure and Assumptions}

The model tracks systemic and tissue levels of benzene, benzene oxide, phenol, and hydroquinone, as well as the total amounts of muconic acid, phenol conjugates, hydroquinone conjugates, and total catechol and trihydroxy benzene (plus conjugates) produced. For benzene, benzene oxide, phenol, and hydroquinone, the body is divided into the following compartments: fat; rapidly perfused tissues, which consist of kidneys, brain, heart, spleen, intestines, and bone marrow; slowly perfused tissues, which contain muscle and skin; blood; and liver, which is the site of metabolism. A stomach lumen compartment and alveolar gas-exchange region were also included for benzene to describe oral and inhalation exposures, respectively. For benzene oxide, phenol, and hydroquinone, separate differential equations were used for the blood compartment, rather than the usual pseudo-steady-state assumption. All metabolites that are represented individually as a single compartment are assumed to be the amount of the metabolite in the urine, that is, a single equation is used to represent the amount of the metabolite excreted in the urine. All compartments are assumed to be well-mixed.

The venous-equilibrium model was used for each tissue compartment; that is, the concentration in the venous blood leaving the compartment was assumed to be at equilibrium with the concentration in the compartment, with $P_{j}^{i}$ being the equilibrium partition coefficient for chemical $i$ in tissue $j$ :

$$
C V_{j}^{i}=\frac{C_{j}^{i}}{P_{j}^{i}}
$$

The total cardiac flow is modeled as the sum of flows to each tissue compartment:

$$
Q_{C a r d}=Q_{F}+Q_{S}+Q_{R}+Q_{L}
$$

The concentration of benzene in the mixed venous blood is given by:

$$
C V^{B Z}=\frac{C V_{F}^{B Z} * Q_{F}+C V_{S}^{B Z} * Q_{S}+C V_{R}^{B Z} * Q_{R}+C V_{L}^{B Z} * Q_{L}}{Q_{\text {Card }}} .
$$


Since the blood:air partition coefficient for benzene is relatively low $\left(P_{B l: A i r}^{B Z}=18\right)$ (Medinsky et al., 1989), a standard pseudo-steady-state gas-exchange equation is used to describe benzene concentration in arterial blood:

$$
C A^{B Z}=\frac{Q_{A v V} C_{I}^{B Z}+Q_{C a r d} C V^{B Z}}{\frac{Q_{A v V}}{P_{B l: A i r}}+Q_{C a r d}} .
$$

(For high partition coefficient values $(\geq 100)$, this relation is not correct because the concentration reaching the gas exchange region is significantly less than the inhaled concentration.)

We assumed that the uptake of orally administered benzene in the body is from the stomach to the liver, where it can be metabolized or distributed to the rest of the body. We also assumed that this is a one-way exchange; once benzene is taken up by the liver it does not return to the stomach lumen. This uptake is represented by a linear equation:

$$
k_{8} A M^{\text {Stom }} \text {. }
$$

Rate equations for the oxidation of benzene to benzene oxide, phenol to hydroquinone and catechol, and hydroquinone to trihydroxy benzene were taken from Lovern et al. (1999) :

$$
\begin{aligned}
R M_{B O}^{B Z} & =k_{1} \frac{V_{2 E 1} C_{L}^{B Z}}{D} C^{M P} T_{L} \\
R M_{H Q}^{P H} & =k_{5} \frac{V_{2 E 1} C_{L}^{P H}}{D} C^{M P} T_{L} \\
R M_{C A}^{P H} & =k_{6} \frac{V_{2 E 1} C_{L}^{P H}}{D} C^{M P} T_{L} \\
R M_{T H B}^{H Q} & =k_{7} \frac{V_{2 E 1} C_{L}^{H Q}}{D} C^{M P} T_{L},
\end{aligned}
$$

where $V_{2 E 1}$ is the activity of CYP2E1 per mg of cytosolic protein as determined by the oxidation of p-nitrophenol to p-nitrocatechol, $C^{M P}$ is the amount of microsomal protein per gram of liver, and

$$
D=1+A^{B Z} C_{L}^{B}+A^{P H} C_{L}^{P H}+A^{H Q} C_{L}^{H Q} .
$$

$A^{B Z}$ was found by taking the inverse of the average of the $K_{m}$ found by Nedelcheva et al. (1999); other rate parameters were taken from Lovern et al. (1999). $T_{L}$ is the total mass of the liver. We assumed that tissue has the same density as water; thus,

$$
T_{L}=V_{L} * \frac{10^{3} g}{1 L}
$$

Rates of metabolism of benzene oxide to muconic acid, phenylmercapturic acid, and phenol are assumed to be first-order:

$$
\begin{aligned}
R M_{P H}^{B O} & =k_{2} C_{L}^{B O} V_{L} \\
R M_{M A}^{B O} & =k_{3} C_{L}^{B O} V_{L} \\
R M_{P M A}^{B O} & =k_{4} C_{L}^{B O} V_{L} .
\end{aligned}
$$


The parameter $k_{2}$ was obtained from work by Lovern et al. (1999); $k_{3}$ and $k_{4}$ were not available from the literature and were estimated in this study. For the rate of metabolism of phenol to its conjugates, the rate equation for the sulfation of phenol from Seaton et al. (1995) was used, since phenyl sulfate is the primary conjugate of phenol formed in vivo:

$$
R M_{C o n j}^{P H}=\left(\frac{V_{P H 1} C_{L}^{P H}}{K_{m, 1}^{P H}+C_{L}^{P H}}+\frac{V_{P H 2} C_{L}^{P H}}{K_{m, 2}^{P H}+C_{L}^{P H}}\right) C^{C P} T_{L} .
$$

This equation was originally developed to model the metabolism of phenol to phenyl sulfate. Our phenol conjugates compartment consisted of phenyl sulfate and phenol glucuronide, but since phenyl sulfate is excreted in much larger amounts than the glucuronide, it was assumed that this expression could represent the metabolism to both conjugates. The $V_{P H 1}, V_{P H 2}, K_{m, 1}^{P H}$, and $K_{m, 2}^{P H}$ found by Seaton et al. (1995) in their in intro studies were used.

The metabolism of HQ to its conjugates is assumed to be represented by the equation for glucuronidation from Seaton et al. (1995):

$$
R M_{C o n j}^{H Q}=\frac{V_{H Q} C_{L}^{H Q}}{K_{m}^{H Q}+C_{L}^{H Q}} C^{M P} T_{L} .
$$

Again, the values for $V_{H Q}$ and $K_{m}^{H Q}$ are taken from the in vitro work of Seaton et al. (1995). While the equation was originally obtained for the metabolism of hydroquinone to hydroquinone glucuronide, the metabolism to hydroquinone sulfate is also included in this model since the amount of sulfate produced is a small fraction of the glucuronide produced.

According to the work by Parke and Williams (1953), two days after dosing part of the administered benzene was still found in the tissues of rabbits and only $80-90 \%$ of the administered dose was found in the excreta. Benzene itself is unlikely to persist this long, and the metabolites of benzene are all water-soluble and readily excreted. This material is most likely bound to tissue macromolecules. Therefore a binding term was considered for phenol and hydroquinone. We assumed this to be a constant times the product of concentration of the tissue and the volume of the tissue, given by the expression

$$
k_{l} C_{j}^{i} V_{j}
$$

where $i$ is the chemical and $j$ is the tissue and $k_{l}$ is the constant for that particular chemical. For phenol, the constant is $k_{9}$ and for hydroquinone, it is $k_{10}$; these two parameters were estimated by fitting to experimental data.

All parameter values taken from the literature are listed in Table 1.

\section{Partition Coefficients}

The only partition coefficients of various tissues and blood that were available from the literature were for benzene. This model requires partition coefficients of various tissues and blood for benzene oxide, phenol, and hydroquinone as well. The partition coefficients for benzene were used for benzene oxide. The partition coefficients for phenol and hydroquinone were obtained by using an algorithm introduced by Poulin and Krishnan (1995a) . Although this is an algorithm intended to predict human 
partition coefficients, we assumed that these were good estimates for mouse partition coefficeints. The algorithm is based on n-Octanol:Water $\left(K_{o / w}\right)$ partition coefficient data. It assumes that the sum of the solubility of a chemical in neutral lipids, phospholipids, and water in a particular tissue or blood is equal to the solubility of the chemical in the tissue or blood, respectively. The partition coefficient is obtained by dividing the estimated solubility of the chemical in a tissue by the estimated solubility of the chemical in blood. For more details of the algorithm, see Poulin and Krishnan (1995a, 1995b). The $K_{o / w}$ values were obtained from Hansch et al. (1995) . For phenol, $K_{o / w}=28.8403$; for hydroquinone, $K_{o / w}=3.89$. Also, the liver:blood partition coefficient was used for the richly perfused:blood partition coefficient for phenol and hydroquinone. The values of the partition coefficients used for phenol and hydroquinone are presented in Table 2.

\section{Parameter Estimation and Maximum Likelihood Estimation}

Optimizations were performed using a combination of Nelder-Mead and Hooke-Jeeves methods (Kelley, 1999). Computations were done in MATLAB (The Math Works, Inc., Natick, Massachusetts).

The model consists of 26 nonlinear ordinary differential equations, which are listed in Appendix B. These equations incorporate the various rates of metabolisms discussed previously.

For our PBPK model, there are seven unknown parameters: $k_{3}$, the rate constant for the metabolism of benzene oxide to muconic acid; $k_{4}$, the rate constant for the metabolism of benzene oxide to phenylmercapturic acid; $k_{8}$, the rate constant for the uptake from the stomach to the liver; $k_{9}$, the binding constant for phenol to tissue; $k_{10}$, the binding constant for hydroquinone to tissue; $C^{C P}$, the concentration of cytosolic protein; and $C^{M P}$, the concentration of microsomal protein. Although values of $C^{C P}$ and $C^{M P}$ have been reported in liver, using these values to estimate the total enzyme activity did not produce accurate estimation of in vivo metabolism. More specifically, the values given by Medinsky et al. (1994) were $82.8 \mathrm{mg} / \mathrm{g}$ liver and $35 \mathrm{mg} / \mathrm{g}$ liver for $C^{C P}$ and $C^{M P}$, respectively. This discrepancy is likely due in part to the fact that CYP2E1 and glucuronide and sulfate transferases are found in other tissues besides the liver and that additional activity must be lumped in with the true hepatic activity to fit the data since the liver is the only metabolizing tissue in our model. To estimate these parameters, we used a modified maximum likelihood estimator similar to the one used by the program SIMUSOLV (Steiner et al., 1990). Since SIMUSOLV is no longer supported by Dow Chemical Company, we provide a derivation of the modified maximum likelihood function (Equation (C4)) in Appendix C.

For each variable for which we have data, there is a heteroscedasticity parameter, $\gamma_{j}$; each $\gamma_{j}$ is bound between 0 and 2 . The closer $\gamma_{j}$ is to 0 , the closer the objective function is to being an absolute error; when $\gamma_{j}$ is close to 2, the closer the objective function is to measuring a relative error. The $\gamma_{j}, j=1, \ldots, 10$ in this study, were estimated as well as the seven unknown model parameters described above.

Since the total number (17) of unknown parameters is large and the heteroscedasticity parameter is not model-related but rather a measure of how well 
the model fits the data, we performed the parameter estimation problem in an iterative process, that is, the optimizations were done first by varying the seven unknown model parameters while keeping the $\gamma_{j}$ fixed. Then, using the most recently found seven optimized parameters, the ten $\gamma_{j}$ were varied and optimized. This process was repeated iteratively until a very small improvement in the parameters was obtained. As a final step, the optimization was performed on all seventeen unknown parameters. This approach, in which the optimization was performed on a smaller subset of parameters, has proven to be computationally very efficient. Finally, to provide some indication that an optimal set of parameters was found, the cost functional was plotted as a function of one parameter at a time while keeping all other parameters fixed. In each case except for the parameter $k_{10}$ (see Figure 2), the plots exhibit similar characteristics as depicted in Figure 3. It is noted that the plots were computed using the nonconstant terms on the right hand side of Equation (C4). These graphs, which do not prove that a global maximum was found, do strongly suggest that a local maximum was obtained.

\section{RESULTS}

The heteroscedasticity, $\gamma_{j}$, associated with the amount of phenol conjugates, hydroquinone conjugates, and benzene exhaled as well as the concentrations of benzene and hydroquinone in the liver were all 2 . The $\gamma_{j}$ was 0.68 for the amount of muconic acid and 0 for the amount of phenylmercapturic acid. For phenol in the liver, $\gamma_{j}$ was 1.41. For the phenol and hydroquinone in the blood, the $\gamma_{j}$ were 1.77 and 1.90 respectively. Thus, the objective function was closer to a relative error than an absolute eror for most parameters since many of the $\gamma_{j}$ were close to or equal to 2 .

Optimal metabolic parameters that were obtained are given in Table 3 . The confidence intervals obtained when one parameter was varied while keeping all other parameters fixed are also given in this table; thus these are intervals obtained when there was one degree of freedom. Using these parameters, the PBPK model predicted the data reasonably well. (See Tables $4-8$ and Figures 4 and 5.) The muconic acid and phenylmercapturic acid data are very accurately predicted. There are variations in the case when the model overpredicts as well as when it underpredicts other data. Tables 4-7 all contain data for phenol conjugates and hydroquinone conjugates. Except at the smallest dose level, the quantity of phenol conjugates is underpredicted. The estimations for the amount of hydroquinone conjugates varied more; the model overpredicted the data from Mathews et al. (1998) while it underpredicted the data from Kenyon et al. (1995).

The data by Sabourin et al. (1988), which were used in the parameter estimation, were the only inhalation exposure data available; all of the other experiments were oral administration. These were also the only tissue dosimetry data. Overall, these predictions were not good, except for the concentration of phenol in the liver, which was predicted accurately. One reason for this lack of accuracy may be due to the fact that extrahepatic metabolism was not considered and this is probably significant for muconic acid, phenylmercapturic acid, phenol conjugates, and hydroquinone conjugates. 


\section{DISCUSSION}

The PBPK model described here takes into account various forms of benzene metabolism, including those mediated by CYP2E1, as well as uptake after both oral and inhalation exposure. Multiple tissue compartments were used for the key metabolites of benzene, while single urinary compartments were used for the metabolites and conjugates of benzene oxide, phenol, and hydroquinone.

While there were good data available concerning the pathways of CYP2E1 and the metabolism of phenol sulfation and hydroquinone glucuronidation, there was little material available on the kinetics or pathways of metabolism of muconic acid or phenylmercapturic acid (Seaton et al., 1994, 1995). The fact that we considered metabolism only in the liver may be a source of error. Although there is little documentation for mice, we know that CYP2E1 is found in the kidneys and lung of rats as well as in the liver. About $10 \%$ of the concentration of CYP2E1 found in the liver was found in the kidney and another 1.5\% in the lung (de Waziers et al., 1990). Also, CYP2E1 is found primarily in the pericentral hepatocytes of zone 3 of the liver rather than throughout the entire liver (Medinsky et al., 1995). Since metabolism in the liver is flow-limited, increasing $C^{M P}$ in the liver results in a less than proportional increase in total metabolism. In the current model there is effectively zero enzymatic activity in the kidney, however, so metabolism in the kidney is not flow-limited but enzyme-limited. Therefore, adding (equations for) enzyme activity to the kidney will have a relatively greater effect per unit of enzyme activity added than increases in the liver, and incorporating these changes might allow us to use the previous found value of $C^{M P}$ without adjustment.

Epoxide hydrolase is found primarily in the centrilobular region of the liver and in the lung of mice. Because of the location of epoxide hydrolase in the liver, metabolism requiring epoxide hydrolase, such as benzene oxide to muconic acid, would primarily be in zone 3 of the liver (Parkinson, 1996). But in rats and humans, epoxide hydrolase is found in the liver, duodenum, jejunum, and kidney; very small amounts of epoxide hydrolase were found in the human ileum as well (de Waziers et al., 1990). When the model is extrapolated to humans, we may need to take into account the other tissues in which epoxide hydrolase is found and in which the metabolism of benzene oxide to muconic acid might occur.

In mice, glutathione S-tranferase was found primarily in the limiting plate hepatocytes of the central vein of the liver as well as in the bronchial epithelium and in the type II alveolar cells of the lung, according to Mainwaring et al. (1996). But Lee (1984) states that glutathione S-tranferase is in the liver, kidney, muscle, and heart. Depending on which source is used, metabolism mediated by glutathione S-tranferase, such as benzene oxide to phenylmercapturic acid, could be occurring throughout the body or primarily in zone 3 of the liver and in the lung. Either way, the current representation of glutathione S-tranferase only in the liver and the representation of the the liver as one homogeneous compartment could be a source of error in the model.

There are also many sources of variability in the data. First of all, using multiple data sets that were from multiple independent experiments could be a source of inaccuracy. For each of these simulations, we used published average body weights, blood flows, and organ volumes since the specific measurements for the mice in the 
individual experiments were unavailable. These data sets also represented both inhalation and gavage administration of benzene. Along with all of these differences, the inhalation exposure data had a large standard deviations, which could be due to significant variations in the pool of mice in the experiment (Sabourin et al., 1988). Given these unavoidable variations, the model did a good job predicting the tissue doses. It would also be helpful if there were more data available in which oral administration experiments measured tissue concentrations or inhalation exposure experiments measured urinary metabolites.

In the future, we hope to improve on this model by looking at the zonal distribution of CYP2E1, UDP-glucuronosyl transferase, phenol sulfotransferase, epoxide hydrolase, and glutathione S-tranferase activity toward metabolites in the liver and developing a three-compartment model for the liver. We will also consider the metabolism in tissues other than the liver, such as the kidney and lung. We then hope to be able to extrapolate the model to humans for use in risk assessment and to incorporate variability or population distribution parameters, such as physiological and metabolic parameters.

Overall, the extrapolation of in vitro rate parameters to the in vivo model has been a qualified success. Multiple tissue compartments were included for benzene as well as the three key metabolites, which had not been done previously. We were able to predict fairly accurately the quantities of metabolites in the urine and of benzene in the exhaled air. We accomplished this by estimating only two parameters, $C^{M P}$ and $C^{C P}$, that had previously published values.

\section{ACKNOWLEDGEMENTS}

The authors thank Dr. Gregory Kedderis and Dr. Rory Connolly for helpful discussions during the preparation of this manuscript and Dr. Barbara Kuyper for editorial assistance. 


\section{Appendices}

\section{Appendix A: Symbols}

The following symbols and abbreviations are used throughout the article. Units of the symbols are given in parentheses.

\section{Chemical Abbreviations}

$B Z$ : Benzene

$B O$ : Benzene Oxide

$P H$ : Phenol

$H Q$ : Hydroquinone

$M A$ : Muconic Acid

$P M A$ : Phenylmercapturic Acid

$P H_{C o n j}$ : Phenol Conjugates

$H Q_{C o n j}$ : Hydroquinone Conjugates

Cat: Catechol

THB: Trihydroxy benzene

\section{Compartment Abbreviations}

$F$ : Fat

$S$ : Slowly or Poorly Perfused Tissue

$R$ : Rapidly or Richly Perfused Tissue

$L$ : Liver

$B l$ : Blood

Stom: Stomach

$I$ : Inhaled air

$E$ : Exhaled air

\section{Primary Symbols}

$C_{j}^{i}$ : Concentration of Chemical i in tissue $\mathrm{j}(\mu \mathrm{mol} / \mathrm{L})$

$C A^{B Z}$ : Concentration of $\mathrm{BZ}$ in the Arterial Blood $(\mu \mathrm{mol} / \mathrm{L})$

$C V^{B Z}$ : Concentration of BZ in Venous Blood $(\mu \mathrm{mol} / \mathrm{L})$

$C V_{j}^{i}$ : Concentration of Chemical i in Venous Blood from tissue $\mathrm{j}(\mu \mathrm{mol} / \mathrm{L})$

$C_{I}^{B Z}$ : Concentration of BZ in Inhaled Air $(\mu \mathrm{mol} / \mathrm{L})$ 
$C_{E}^{B Z}$ : Concentration of BZ in Exhaled Air $(\mu \mathrm{mol} / \mathrm{L})$

$A M^{i}$ : Amount of Chemical i in Urine $(\mu \mathrm{mol})$

$A M^{\text {Stom }}$ : Amount of BZ in the Stomach $(\mu \mathrm{mol})$

$R M_{j}^{i}$ : Rate of Metabolism of Chemical i to Chemical j ( $\mu \mathrm{mol} / \mathrm{hr}$ )

$Q_{j}$ : Flow in tissue $\mathrm{j}(\mathrm{L} / \mathrm{hr})$

$Q_{A v V}:$ Alveolar Ventilation $(\mathrm{L} / \mathrm{hr})$

$Q_{\text {Card }}$ : Cardiac Output (L/hr)

$P_{j}^{i}:$ Tissue j/Blood Partition Coefficient for Chemical i

$P_{B l: A i r}^{B Z}:$ Blood/Air Partition Coefficient for BZ

$B W$ : Body Weight $(\mathrm{kg})$

$V_{j}$ : Volume of Tissue $\mathrm{j}(\mathrm{L})$

$T_{L}$ : Total mass of the Liver $(\mathrm{g})$

$C^{M P}$ : Concentration of Microsomal Protein per gram of tissue in the Liver $(\mathrm{mg} / \mathrm{g})$

$C^{C P}$ : Concentration of Cytosolic Protein per gram of tissue in the Liver $(\mathrm{mg} / \mathrm{g}$ )

$V_{2 E 1}$ : CYP2E1 specific activity as determined by the oxidation of p-nitrophenol to p-nitrocatechol (nmol/mg/hr)

$A^{i}$ : Affinity parameter for CYP2E1 for substrate i $(\mathrm{L} / \mu \mathrm{mol})$

$k_{1}, k_{5}-k_{7}$ : Efficiencies of CYP2E1 for specific oxidations relative to $V_{2 E 1}(\mathrm{~L} / \mathrm{nmol})$

$k_{2}-k_{4}, k_{8}-k_{10}$ : First-order rate constants $(1 / \mathrm{hr})$

$V_{P H 1}, V_{P H 2}$ : Maximum rates of metabolism of $\mathrm{PH}$ by two sulfate transferases $(\mu \mathrm{mol} / \mathrm{mg} / \mathrm{hr})$

$K_{m, 1}^{P H}, K_{m, 2}^{P H}$ : Concentrations at half-saturation of $\mathrm{PH}$ by two sulfate transferases $(\mu \mathrm{mol} / \mathrm{L})$

$K_{m, 2}^{P H}$ : Concentration at half-saturation for TL form of $\mathrm{PH}(\mu \mathrm{mol} / \mathrm{L})$

$V_{H Q}$ : Maximum rate of metabolism for $\mathrm{HQ}(\mu \mathrm{mol} / \mathrm{mg} / \mathrm{hr})$

$K_{m}^{H Q}$ : Concentration at half-saturation for $\mathrm{HQ}(\mu \mathrm{mol} / \mathrm{L})$ 


\section{Appendix B: Differential Equations}

The following differential equations were derived using basic mass balance principles and incorporate the metabolism rate equations discussed previously. Equations are grouped by chemical.

\section{Benzene}

$$
\begin{aligned}
\text { Fat: } V_{F} \frac{d C_{F}^{B Z}}{d t} & =Q_{F} *\left(C A^{B Z}-C V_{F}^{B Z}\right) \\
\text { Slowly: } V_{S} \frac{d C_{S}^{B Z}}{d t} & =Q_{S} *\left(C A^{B Z}-C V_{S}^{B Z}\right) \\
\text { Rapidly: } V_{R} \frac{d C_{R}^{B Z}}{d t} & =Q_{R} *\left(C A^{B Z}-C V_{R}^{B Z}\right) \\
\text { Liver: } V_{L} \frac{d C_{L}^{B Z}}{d t} & =Q_{L} *\left(C A^{B Z}-C V_{L}^{B Z}\right)-R M_{B O}^{B Z}+k_{8} A M^{S t o m} \\
\text { Stomach: } \frac{d A M^{S t o m}}{d t} & =-k_{8} A M^{S t o m} \\
\text { Exhaled: } \frac{d A M_{E}^{B Z}}{d t} & =Q_{C a r d}\left(C V^{B Z}-C A^{B Z}\right)+Q_{A v V} * C_{I}^{B Z}
\end{aligned}
$$

$\underline{\text { Benzene Oxide }}$

Blood: $\begin{array}{rl}V_{B l} \frac{d C_{B l}^{B O}}{d t}=Q_{F} & * C V_{F}^{B O}+Q_{S} * C V_{S}^{B O}+Q_{R} * C V_{R}^{B O} \\ & +Q_{L} * C V_{L}^{B O}-Q_{C a r d} * C_{B l}^{B O}\end{array}$

Fat: $V_{F} \frac{d C_{F}^{B O}}{d t}=Q_{F} *\left(C_{B l}^{B O}-C V_{F}^{B O x}\right)$

Slowly: $V_{S} \frac{d C_{S}^{B O}}{d t}=Q_{S} *\left(C_{B l}^{B O}-C V_{S}^{B O}\right)$

Rapidly: $V_{R} \frac{d C_{R}^{B O}}{d t}=Q_{R} *\left(C_{B l}^{B O}-C V_{R}^{B O}\right)$

Liver: $V_{L} \frac{d C_{L}^{B O}}{d t}=Q_{L} *\left(C_{B l}^{B O}-C V_{L}^{B O}\right)+R M_{B O}^{B Z}-R M_{P H}^{B O}$

$$
-R M_{M A}^{B O}-R M_{P M A}^{B O}
$$

$\underline{\text { Muconic Acid }}$

$$
\frac{d A M^{M A}}{d t}=R M_{M A}^{B O}
$$

Phenylmercapturic Acid

$$
\frac{d A M^{P M A}}{d t}=R M_{P M A}^{B O}
$$


$\underline{\text { Phenol }}$

Blood: $V_{B l} \frac{d C_{B l}^{P H}}{d t}=Q_{F} * C V_{F}^{P H}+Q_{S} * C V_{S}^{P H}+Q_{R} * C V_{R}^{P H}$

$$
+Q_{L} * C V_{L}^{P H}-Q_{C a r d} * C_{B l}^{P H}-k_{9} C_{B l}^{P H} V_{B l}
$$

Fat: $V_{F} \frac{d C_{F}^{P H}}{d t}=Q_{F} *\left(C_{B l}^{P H}-C V_{F}^{P H}\right)-k_{9} C_{B l}^{P H} V_{F}$

Slowly: $V_{S} \frac{d C_{S}^{P H}}{d t}=Q_{S} *\left(C_{B l}^{P H}-C V_{S}^{P H}\right)-k_{9} C_{S}^{P H} V_{S}$

Rapidly: $V_{R} \frac{d C_{R}^{P H}}{d t}=Q_{R} *\left(C_{B l}^{P H}-C V_{R}^{P H}\right)-k_{9} C_{R}^{P H} V_{R}$

Liver: $V_{L} \frac{d C_{L}^{P H}}{d t}=Q_{L} *\left(C_{B l}^{P H}-C V_{L}^{P H}\right)+R M_{P H}^{B O}-R M_{H Q}^{P H}$

$$
-R M_{C A}^{P H}-R M_{C o n j}^{P H}-k_{9} C_{L}^{P H} V_{L}
$$

$\underline{\text { Phenol Conjugates }}$

$$
\frac{d A M^{P H-C o n j}}{d t}=R M_{\text {Conj }}^{P H}
$$

$\underline{\text { Hydroquinone }}$

Blood: $V_{B l} \frac{d C_{B l}^{H Q}}{d t}=Q_{F} * C V_{F}^{H Q}+Q_{S} * C V_{S}^{H Q}+Q_{R} * C V_{R}^{H Q}$

$$
+Q_{L} * C V_{L}^{H Q}-Q_{C a r d} * C_{B l}^{H Q}-k_{10} C_{B l}^{H Q} V_{B l}(20)
$$

Fat: $V_{F} \frac{d C_{F}^{H Q}}{d t}=Q_{F} *\left(C_{B l}^{H Q}-C V_{F}^{H Q}\right)-k_{10} C_{F}^{H Q} V_{F}$

Slowly: $V_{S} \frac{d C_{S}^{H Q}}{d t}=Q_{S} *\left(C_{B l}^{H Q}-C V_{S}^{H Q}\right)-k_{10} C_{S}^{H Q} V_{S}$

Rapidly: $V_{R} \frac{d C_{R}^{H Q}}{d t}=Q_{R} *\left(C_{B l}^{H Q}-C V_{R}^{H Q}\right)-k_{10} C_{R}^{H Q} V_{R}$

$$
\text { Liver: } V_{L} \frac{d C_{L}^{H Q}}{d t}=Q_{L} *\left(C_{B l}^{H Q}-C V_{L}^{H Q}\right)+R M_{H Q}^{P H}-R M_{T H B}^{H Q}
$$

$$
-R M_{C o n j}^{H Q}-k_{10} C_{L}^{H Q} V_{L}
$$

Catechol and Trihydroxy benzene

$$
\frac{d A M^{C A / T H B}}{d t}=R M_{C A}^{P H}+R M_{T H B}^{H Q}
$$

$\underline{\text { Hydroquinone Conjugates }}$

$$
\frac{d A M^{H Q-C o n j}}{d t}=R M_{C o n j}^{H Q}
$$




\section{Appendix C: Parameter Estimation and Maximum Likelihood Estimator}

The maximum likelihood estimator is known to be both consistent and asymptotically efficient. Although it is highly favored when looking at large samples, there are usually no optimal properties when considering small samples (Bard, 1974). Models where the dependent variables are written in terms of independent variables and parameters are called reduced models. If the functions are linear in the parameters, we call this a linear reduced model; if the independent variables of the reduced model are measured precisely, we call this a standard reduced model (Bard, 1974).

Let us first consider the Yonathan Bard's likelihood standard reduced model (Bard, 1974):

$$
L\left(\theta, V_{1}, \ldots, V_{n}\right)=(2 \pi)^{-\frac{n r}{2}} \Pi_{j=1}^{n}\left|V_{j}\right|^{-\frac{1}{2}} \cdot e^{-\frac{1}{2} \sum_{j=1}^{n}\left[\vec{z}_{j}-\vec{f}\left(x_{j}, \theta\right)\right]^{T} V_{j}^{-1}\left[\vec{z}_{j}-\vec{f}\left(x_{j}, \theta\right)\right]}
$$

where

- $\theta$ is the set of parameter values.

- $r$ is the number of response (dependent) variables.

- $n_{i}$ is the number of measurements of the $i$ th response.

- $n$ is the total number of measurements, i.e., $n=\sum_{i=1}^{r} n_{i}$.

- $\vec{z}_{j}$ is the observed value at the $j$ th data point.

- $z_{i, j}$ is the observed value of the $i$ th response at the $j$ th data point.

- $\vec{f}\left(x_{j}, \theta\right)$ is the predicted value at the $j$ th data point.

- $f_{i, j}$ is the predicted value of the $i$ th response at the $j$ th data point.

- $V_{j}$ is the variance-covariance matrix of the $j$ th data point and is a diagonal matrix.

Now taking the log of both sides, we obtain

$$
\begin{aligned}
\log L\left(\theta, V_{1}, \ldots, V_{n}\right)=-\frac{n r}{2} \log (2 \pi)-\frac{1}{2} \sum_{j=1}^{n} \log \left|V_{j}\right| \\
\quad-\frac{1}{2} \sum_{j=1}^{n}\left[\overrightarrow{z_{j}}-\vec{f}\left(x_{j}, \theta\right)\right]^{T} V_{i}^{-1}\left[\vec{z}_{j}-\vec{f}\left(x_{j}, \theta\right)\right] .
\end{aligned}
$$

Next, substituting the following notation

- $\phi=\log L\left(\theta, V_{1}, \ldots, V_{n}\right)$

- $\overrightarrow{f_{j}}=\vec{f}\left(x_{j}, \theta\right)$. 
in equation $(\mathrm{C} 2)$ yields

$$
\phi=-\frac{n r}{2} \log (2 \pi)-\frac{1}{2} \sum_{j=1}^{n} \log \left|V_{j}\right|-\frac{1}{2} \sum_{j=1}^{n}\left(\vec{z}_{j}-\vec{f}_{j}\right)^{T} V_{j}^{-1}\left(\vec{z}_{j}-\vec{f}_{j}\right) .
$$

We assume that the errors from response variable to response variable are uncorrelated; therefore, the $V_{j}$ matrix for each $j=1, \ldots, n$ is diagonal. Thus,

$$
\left|V_{j}\right|=V_{j_{11}} \cdot V_{j_{22}} \cdot \ldots \cdot V_{j_{r r}} \quad j=1, \ldots, n .
$$

Making this substitution,

$$
\begin{aligned}
\phi & =-\frac{n r}{2} \log (2 \pi)-\frac{1}{2} \sum_{j=1}^{n} \log \left(\prod_{i=1}^{r} V_{j_{i i}}\right)-\frac{1}{2} \sum_{j=1}^{n} \sum_{i=1}^{r} \frac{1}{V_{j_{i i}}}\left(z_{i, j}-f_{i, j}\right)^{2} \\
& =-\frac{n r}{2} \log (2 \pi)-\frac{1}{2} \sum_{j=1}^{n} \sum_{i=1}^{r} \log V_{j_{i i}}-\frac{1}{2} \sum_{j=1}^{n} \sum_{i=1}^{r} \frac{1}{V_{j_{i i}}}\left(z_{i, j}-f_{i, j}\right)^{2} .
\end{aligned}
$$

The equation (C3) is to be maximized with respect to the two parameters $\theta$ and $V_{j_{i i}}$. To carry out this optimization problem, the method of stagewise maximization (Bard, 1974) is employed. That is, for any value of $\theta$, we find the values of $V_{j_{i i}}$ that maximize $\phi$. Thus each $V_{j_{i i}}$ will be a function of $\theta$ and, consequently, when these are substituted in (C3), $\phi$ will be a function of $\theta$ only, which we denote by $\tilde{\phi}(\theta)$. We then seek $\theta^{*}$ to maximize $\tilde{\phi}(\theta)$. To this end, we assume the errors from experiment to experiment are uncorrelated, $V_{j} \neq V_{k}$ for $j \neq k$, and the following functional form for the error of each response variable

$$
V_{j_{i i}}=w_{i}^{2} f_{i, j}^{\gamma_{i}}
$$

where $w_{i}$ is a proportional factor and $\gamma_{i}$ is an adjustable parameter between 0 and 2 inclusive and is called the heteroscedasticity parameter. Next, we differentiate (C3) with respect to $w_{i}$ to obtain

$$
\frac{\partial \phi}{\partial w_{i}}=-\frac{n}{w_{i}}+\sum_{j=1}^{n} \frac{\left(z_{i, j}-f_{i, j}\right)^{2}}{w_{i}^{3} f_{i, j}^{\gamma_{i}}}
$$

and equate the derivatives to zero to get

$$
w_{i}^{2}=\frac{1}{n} \sum_{j=1}^{n} \frac{\left(z_{i, j}-f_{i, j}\right)^{2}}{f_{i, j}^{\gamma_{i}}} .
$$

Substituting the expression $V_{j_{i i}}=w_{i}^{2} f_{i, j}^{\gamma_{j}}$, where $w_{i}^{2}$ are given above, into (C3), we get

$$
\begin{aligned}
\tilde{\phi}(\theta)=-\frac{1}{2} \sum_{i=1}^{r}\left\{n_{i}[\log (2 \pi)+1]\right. \\
\left.\quad+\gamma_{i} \sum_{j=1}^{n_{i}} \log f_{i, j}+n_{i} \log \left(\frac{1}{n_{i}} \sum_{j=1}^{n_{i}} \frac{\left(z_{i, j}-f_{i, j}\right)^{2}}{f_{i, j}^{\gamma_{i}}}\right)\right\} .
\end{aligned}
$$

This is the cost function for the maximum likelihood formulation that is used in our parameter estimation problem. 


\section{References}

Andrews, L. S., Sasame, H., and Gilletter, J. R. 1979. ${ }^{3}$ h-benzene metabolism in rabbit bone marrow. Life Sci. 25(7):567-572.

Bard, Y. 1974. Nonlinear Parameter Estimation. Academic Press.

Chaney, A. M. and Carlson, G. P. 1995. Comparison of rat hepatic and pulmonary microsomal metabolism of benzene and the lack of benzene-induced pneumontoxicity and hepatotoxicity. Toxicol. 104:53-62.

Collins, A. S., Sumner, S. C., Borghoff, S. J., and Medinsky, M. A. 1999. A physiological model for tert-Amyl methyl ether and tert-Amyl alcohol: Hypothesis testing of model structures. Toxicol. Sci. 49:15=28.

de Waziers, I., Cugnenc, P., Lang, C., Leroux, J.-P., and Beaune, P. 1990. Cytochrome $\mathrm{P} 450$ isoenzymes, epoxide hydrolase and glutathione transferases in rat and human hepatic and extrahepatic tissues. J. Pharmacol. Exp. Ther. 253(1):387-394.

Hansch, C., Leo, A., and Hoekman, D. 1995. Exploring QSAR: Hydrophobic, Electronic, and Steric Constants. The American Chemical Society.

Inoue, O., Seiji, K., Kasahara, M., Nakatsuka, H., Watanabe, T., Yin, S.-G., Li, G.-L., Cai, S.-X., and Ikeda, M. 1988. Determination of catechol and quinol in the urine of workers exposed to benzene. Br. J. Ind. Med. 45:487-492.

Kalf, G. 1987. Recent advances in the metabolism and toxicity of benzene. CRC Crit. Rev. Toxicol. 18:?

Kelley, C. 1999. Iterative Methods for Optimization. SIAM.

Kenyon, E. M., Seeley, M. E., Janszen, D., and Medinsky, M. A. 1995. Dose-, route-, and sex-dependent urinary excretion of phenol metabolites of $\mathrm{B}_{6} \mathrm{C} 3 \mathrm{~F}_{1}$ mice. $J$. Toxicol. Environ. Health 44:219-233.

Lee, C.-Y. G. 1984. Multiple forms of mouse glutathione s-transferase. Biochem. Soc. Trans. 12(1):30-33.

Legathe, A., Hoener, B.-A., and Tozer, T. N. 1994. Pharmacokinetic interaction between benzene metabolites, phenol and hydroquinone, in $\mathrm{B} 6 \mathrm{C} 3 \mathrm{~F} 1$ mice. Toxicol. Appl. Pharmacol. 124:131-138.

Leung, H.-W., Poland, A., Paustenbach, D. J., Murray, F. J., and Andersen, M. E. 1990. Phamacokinetics of [125I]-2-Iodo-3,7,8-trichloroibenzo-p-dioxin in mice: Analysis with a physiological modeling approach. Toxicol. Appl. Pharmacol. 103:411-419.

Lindstrom, A. B., Yeowell-O'Connell, K., Waidyanatha, S., Golding, B. T., Tornero-Velez, R., and Rappaport, S. M. 1997. Measurement of benzene oxide in the blood of rats following administration of benzene. Carcinogenesis 18(8):1637-1641.

Lovern, M. R., Maris, M. E., and Schlosser, P. M. 1999. Use of a mathematical model of rodent in vitro benzene metabolism to predict human in vitro metabolism data. Carcinogenesis 20(8):1511-1520. 
MacEachern, L., Snyder, R., and Laskin, D. 1992. Alterations in the morphology and functional activity of bone marrow phagocytes following benzene treatment in mice. Toxicol. Appl. Pharmacol. 117:147-154.

Mainwaring, G. M., Williams, S. M., Foster, J. R., Tugwood, J., and Green, T. 1996. The distribution of theta-class glutathione s-transferases in the liver and lung of mouse, rat and human. Biochem. J. 318:297-303.

Maltoni, C., Conti, B., and Cotti, G. 1983. Benzene: a multipotential carcinogen. Results of long-term bioassays performed at the bologna institute of oncology. Am. J. Ind. Med. 4:589-630.

Maltoni, C., Conti, B., Cotti, G., and Belpoggi, F. 1985. Experimental studies on benzene carcinogenicity at the bologna institute of oncology: current results and ongoing research. Am. J. Ind. Med. 7:415-446.

Mathews, J. M., Etheridge, A. S., and Matthews, H. 1998. Dose-dependent metabolism of benzene in hamsters, rats, and mice. Toxicol. Sci. 44:14-21.

Medinsky, M. A., Kenyon, E. M., and Schlosser, P. M. 1995. Benzene: a case study in parent chemical and metabolite interactions. Toxicol. 105:225-233.

Medinsky, M. A., Leavens, T. L., Csanady, G. A., Gargas, M. L., and Bond, J. A. 1994. In vivo metabolism of butadience by mice and rats: a comparison of physiological model predictions and experimental data. Carcinogenesis 15(7):1329-1340.

Medinsky, M. A., Sabourin, P. J., Lucier, G., Birnbaum, L. S., and Henderson, R. F. 1989. A physiological model for simulation of benzene metabolism in rats and mice. Toxicol. Appl. Pharmacol. 99:193-206.

Nedelcheva, V., Gut, I., Soucek, P., Tichavska, B., Tynkova, L., Mraz, J., Guengerich, F. P., and Indelman-Sundberg, M. 1999. Metabolism of benzene in human liver microsomes: individual variations in relation to CYP2E1 expression. Arch. Toxicol. 73:33-40.

Parke, D. and Williams, R. 1953. Studies in detoxification: 49. the metabolism of benzene containing $\left[{ }^{14} C_{1}\right]$ benzene. J. Biochem. 54:231-238.

Parke, D. V. 1996. Personal reflections on 50 years of study in benzene toxicology. Environ. Health Perspect. 104:1123-1128.

Parkinson, A. 1996. Biotransformation of xenobiotics. In Klaassen, C. D., editor, Casarett and Doull's Toxicology: The Basic Science of Poisons pages 113-186. McGraw-Hill, Inc. 5 edition.

Poulin, P. and Krishnan, K. 1995a. An algorithm for predicting tissue:blood partition coefficients of organic chemicals from n-octanol:water partition coefficient data. J. Toxicol. Environ. Health 46:117-129.

Poulin, P. and Krishnan, K. 1995b. A biologically-based algorithm for predicting human tissue:blood partition coefficients of organic chemicals. Hum. Exp. Toxicol. 14:273-280. 
Rothman, N., Smith, M. T., Hayes, R. B., Traver, R. D., ann Hoener, B., Campleman, S., Li, G.-L., Dosemeci, M., Linet, M., Zhang, L., Xi, L., Wacholder, S., Lu, W., Meyer, K. B., Titenko-Holland, N., Stewart, J. T., Yin, S., and Ross, D. 1997. Benzene poisoning, a risk factor for hematological malignancy, is associated with the $\mathrm{NQO}^{609} \mathrm{C} \rightarrow \mathrm{T}$ mutation and rapid fractional excretion of chlorzoxazone. Cancer Res. 57:2839-2842.

Sabourin, P. J., Bechtold, W. E., Birnbaum, L. S., Lucier, G., and Henderson, R. F. 1988. Differences in the metabolism and disposition of inhaled $\left[{ }^{3} H\right]$ benzene by F344/N rats and B6C3F 1 mice. Toxicol. Appl. Pharmacol. 94:128-140.

Sabourin, P. J., Chen, B. T., Lucier, G., Birnbaum, L. S., Fisher, E., and Henderson, R. F. 1987. Effect of dose on the absorption and excretion of $\left[{ }^{14} C\right]$ benzene administered orally or by inhalation in rats and mice. Toxicol. Appl. Pharmacol. $87: 325-336$.

Seaton, M. J., Schlosser, P. M., Bond, J. A., and Medinsky, M. A. 1994. Benzene metabolism by human liver microsomes in relation to cytochrome P450 2E1 activity. Carcinogenesis 15(9):1799-1806.

Seaton, M. J., Schlosser, P. M., and Medinsky, M. A. 1995. In vitro conjugation of benzene metabolites by human liver: potential influence of interindividual variability on benzene toxicity. Carcinogenesis 16(7):1519-1527.

Smith, M. T. 1996. Overview of benzene-induced aplastic anaemia. Eur. J. Haematol. 57:107-110.

Snyder, R., Chepiga, T., Yang, C. S., Thomas, H., Platt, K., and Oesch, F. 1993. Benzene metabolism by reconstituted cytocharomes P450 2B1 and 2E1 and its modulation by cytochrome $b_{5}$, microsomal epoxide hydrolase, and glutathione transferases: Evidence for an important role of microsomal epoxide hydrolase in the formation of hydroquinone. Toxicol. Appl. Pharmacol. 122:172-181.

Steiner, E., Rey, T., and McCroskey, P. 1990. Simusolv Reference Guide. Dow Chemical Company Midland, Michigan.

Valentine, J., Lee, S., Seaton, M., Asgharian, B., Farris, G., Corton, J., Gonzalez, F., and Medinsky, M. 1996. Reduction of benzene metabolism and toxicity in mice that lack CYP2E1 expression. Toxicol. Appl. Pharmacol. 141:205-213.

Wallace, L. 1990. Major sources of exposure to benzene and other volatile organic chemicals. Risk Anal. 10(1):59-64.

Yardley-Jones, A., Anderson, D., and Parke, D. 1991. The toxicity of benzene and its metabolism and molecular pathology in human risk assessment. Br. J. Ind. Med. 48:437-444. 
Table 1: Parameter Values from Literature

\begin{tabular}{|c|c|c|c|}
\hline Parameter & Value & Unit & Source \\
\hline$B W$ & 0.030 & $\mathrm{~kg}$ & Medinsky et al., 1989 \\
\hline$P_{B l: A i r}^{B Z}$ & 18 & & Medinsky et al., 1989 \\
\hline$P_{F}^{B Z}$ & 28 & & Medinsky et al., 1989 \\
\hline$P_{L}^{B Z}$ & 1 & & Medinsky et al., 1989 \\
\hline$P_{S}^{B Z}$ & 0.6 & & Medinsky et al., 1989 \\
\hline$P_{R}^{B Z}$ & 1 & & Medinsky et al., 1989 \\
\hline$Q_{A v V}$ & $41 * \mathrm{BW}$ & $\mathrm{L} / \mathrm{hr}$ & Medinsky et al., 1994 \\
\hline$Q_{\text {Card }}$ & $Q_{A v V}$ & $\mathrm{~L} / \mathrm{hr}$ & Medinsky et al., 1994 \\
\hline$Q_{L}$ & $0.25^{*} Q_{C a r d}$ & $\mathrm{~L} / \mathrm{hr}$ & Medinsky et al., 1994 \\
\hline$Q_{F}$ & $0.09^{*} Q_{C a r d}$ & $\mathrm{~L} / \mathrm{hr}$ & Medinsky et al., 1994 \\
\hline$Q_{S}$ & $0.15^{*} Q_{C a r d}$ & $\mathrm{~L} / \mathrm{hr}$ & Medinsky et al., 1994 \\
\hline$Q_{R}$ & $0.51^{*} Q_{C a r d}$ & $\mathrm{~L} / \mathrm{hr}$ & Medinsky et al., 1994 \\
\hline$V_{L}$ & $0.0624^{*} \mathrm{BW}$ & $\mathrm{L}$ & Medinsky et al., 1994 \\
\hline$V_{F}$ & $0.1^{*} \mathrm{BW}$ & $\mathrm{L}$ & Medinsky et al., 1994 \\
\hline$V_{S}$ & $0.70^{*} \mathrm{BW}$ & $\mathrm{L}$ & Medinsky et al., 1994 \\
\hline$V_{R}$ & $0.0226 * \mathrm{BW}$ & $\mathrm{L}$ & Medinsky et al., 1994 \\
\hline$V_{B l}$ & $0.05 * \mathrm{BW}$ & $\mathrm{L}$ & Leung et al., 1990 \\
\hline$V_{2 E 1}$ & 141 & $\mathrm{nmol} / \mathrm{mg} / \mathrm{hr}$ & Unpublished results \\
\hline$V_{P H 1}$ & 0.0221 & $\mu \mathrm{mol} / \mathrm{mg}$ protein $/ \mathrm{hr}$ & Seaton et al., 1995 \\
\hline$V_{P H 2}$ & 0.295 & $\mu \mathrm{mol} / \mathrm{mg}$ protein $/ \mathrm{hr}$ & Seaton et al., 1995 \\
\hline$V_{H Q}$ & 1.0456 & $\mu \mathrm{mol} / \mathrm{mg}$ protein $/ \mathrm{hr}$ & Seaton et al., 1995 \\
\hline$K_{m, 1}^{P H}$ & 1.4 & $\mu \mathrm{mol} / \mathrm{L}$ & Seaton et al., 1995 \\
\hline$K_{m, 2}^{P H}$ & 220 & $\mu \mathrm{mol} / \mathrm{L}$ & Seaton et al., 1995 \\
\hline$K_{m}^{H Q}$ & 746 & $\mu \mathrm{mol} / \mathrm{L}$ & Seaton et al., 1995 \\
\hline$A^{B Z}$ & 0.0397 & $\mathrm{~L} / \mu \mathrm{mol}$ & Nedelcheva et al., 1999 \\
\hline$A^{P H}$ & $1.30 * 10^{-2}$ & $\mathrm{~L} / \mu \mathrm{mol}$ & Lovern et al., 1999 \\
\hline$A^{H Q}$ & $10^{-7}$ & $\mathrm{~L} / \mu \mathrm{mol}$ & Lovern et al., 1999 \\
\hline$k_{1}$ & $4.20 * 10^{-5}$ & $\mathrm{~L} / \mathrm{nmol}$ & Lovern et al., 1999 \\
\hline$k_{2}$ & 32.16 & $1 / \mathrm{hr}$ & Lovern et al., 1999 \\
\hline$k_{5}$ & $4.00^{*} 10^{-5}$ & $\mathrm{~L} / \mathrm{nmol}$ & Lovern et al., 1999 \\
\hline$k_{6}$ & $2.13^{*} 10^{-6}$ & $\mathrm{~L} / \mathrm{nmol}$ & Lovern et al., 1999 \\
\hline$k_{7}$ & $2.03 * 10^{-7}$ & $\mathrm{~L} / \mathrm{nmol}$ & Lovern et al., 1999 \\
\hline
\end{tabular}


Table 2: Partition Coefficients*

\begin{tabular}{cc}
\hline Parameter & Value \\
\hline$P_{F}^{P H}$ & 4.34 \\
$P_{L}^{P H}$ & 0.94 \\
$P_{S}^{P H}$ & 1.06 \\
$P_{R}^{P H}$ & 1.06 \\
$P_{F}^{H Q}$ & 4.06 \\
$P_{L}^{H Q}$ & 0.94 \\
$P_{S}^{H Q}$ & 1.04 \\
$P_{R}^{H Q}$ & 1.04 \\
\hline
\end{tabular}

* Estimated by method of Poulin and Krishnan (1995a)

Table 3: Estimated Parameters

\begin{tabular}{ccc}
\hline Parameter & Value & Confidence Interval $^{*}$ \\
\hline$k_{3}$ & $2.0451 / \mathrm{hr}$ & {$[2.041,2.049]$} \\
$k_{4}$ & $0.851 / \mathrm{hr}$ & {$[0.849,0.852]$} \\
$k_{8}$ & $7.301 / \mathrm{hr}$ & {$[7.15,7.58]$} \\
$k_{9}$ & $29.581 / \mathrm{hr}$ & {$[29.4,29.9]$} \\
$k_{10}$ & $4211 / \mathrm{hr}$ & {$[55,1550]$} \\
$C^{C P}$ & $57.3 \mathrm{mg} / \mathrm{g}$-tissue & {$[57.28,57.33]$} \\
$C^{M P}$ & $387 \mathrm{mg} / \mathrm{g}$-tissue & {$[386.95,387.05]$} \\
\hline
\end{tabular}

* Interval determined by change in log likelihood value corresponding to a $p$ value of 0.05 on a chi-squared distribution with 1 degree of freedom (Collins et al., 1999). 
Table 4: Oral Dose of $0.1 \mathrm{mg} / \mathrm{kg}$-Body Weight

\begin{tabular}{lcc}
\hline Amount & $\begin{array}{c}\text { Experimental } \\
\text { Data(Mathews et al., 1998) } \\
(\mu \mathrm{mol})\end{array}$ & $\begin{array}{c}\text { Model } \\
\text { Results } \\
(\mu \mathrm{mol})\end{array}$ \\
\hline MA at $\mathrm{t}=24$ hours & $0.0328 \pm 0.0041$ & 0.0221 \\
PMA at $\mathrm{t}=24$ hours & $0.0123 \pm 0.0034$ & 0.0092 \\
PH Conjugates at $\mathrm{t}=24$ hours & $0.0574 \pm 0.0015$ & 0.1008 \\
HQ Conjugates at $\mathrm{t}=24$ hours & $0.0746 \pm 0.0035$ & 0.1125 \\
\hline
\end{tabular}

Table 5: Oral Dose of $100 \mathrm{mg} / \mathrm{kg}$-Body Weight

\begin{tabular}{lcc}
\hline Amount & $\begin{array}{c}\text { Experimental Data } \\
(\text { Mathews et al., 1998) } \\
(\mu \mathrm{mol})\end{array}$ & $\begin{array}{c}\text { Model } \\
\text { Results } \\
(\mu \mathrm{mol})\end{array}$ \\
\hline MA at $\mathrm{t}=24$ hours & $11.1718 \pm 1.5919$ & 11.2602 \\
PMA at $\mathrm{t}=24$ hours & $4.6803 \pm 1.5919$ & 4.6801 \\
PH Conjugates at $\mathrm{t}=24$ hours & $37.7096 \pm 1.6586$ & 32.9423 \\
HQ Conjugates at $\mathrm{t}=24$ hours & $27.4339 \pm 1.9732$ & 56.4435 \\
\hline
\end{tabular}

Table 6: Oral Dose of $1 \mathrm{mg} / \mathrm{kg}$-Body Weight

\begin{tabular}{lcc}
\hline Amount & $\begin{array}{c}\text { Experimental Data } \\
\text { (Kenyon et al., 1955) } \\
(\mu \mathrm{mol})\end{array}$ & $\begin{array}{c}\text { Model } \\
\text { Results } \\
(\mu \mathrm{mol})\end{array}$ \\
\hline PH Conjugates at $\mathrm{t}=48$ hours & $1.1598 \pm 0.0230$ & 0.9180 \\
HQ Conjugates at $\mathrm{t}=48$ hours & $1.6514 \pm 0.0307$ & 1.1617 \\
\hline
\end{tabular}


Table 7: Oral Dose of $10 \mathrm{mg} / \mathrm{kg}$-Body Weight

\begin{tabular}{lcc}
\hline & $\begin{array}{c}\text { Experimental Data } \\
\text { (Kenyon et al., 1995) } \\
(\mu \mathrm{mol})\end{array}$ & $\begin{array}{c}\text { Model } \\
\text { Results } \\
(\mu \mathrm{mol})\end{array}$ \\
\hline PHount & $14.5557 \pm 0.4225$ & 6.7854 \\
HQ Conjugates at $\mathrm{t}=48$ hours & $13.8260 \pm 0.1536$ & 10.2232 \\
\hline
\end{tabular}

Table 8: 6-hour 50 ppm Inhalation Exposure

\begin{tabular}{lcc}
\hline Concentration & $\begin{array}{c}\text { Experimental Data } \\
\text { Sabourin et al., 1988 }) \\
(\mu \mathrm{mol} / \mathrm{L})\end{array}$ & $\begin{array}{c}\text { Model } \\
\text { Results } \\
(\mu \mathrm{mol} / \mathrm{L})\end{array}$ \\
\hline BZ in Liver at $\mathrm{t}=6$ & $4.5 \pm 0.9$ & 0.4900 \\
$\mathrm{PH}$ in Liver at $\mathrm{t}=6$ & $0.3 \pm 0.1$ & 0.3000 \\
$\mathrm{HQ}$ in Liver at $\mathrm{t}=6$ & $2.1 \pm 0.3$ & 0.5834 \\
$\mathrm{PH}$ in Blood at $\mathrm{t}=6$ & $1.3 \pm 1.1$ & 0.0657 \\
$\mathrm{HQ}$ in Blood at $\mathrm{t}=6$ & $4.3 \pm 4.0$ & 0.1207 \\
\hline
\end{tabular}




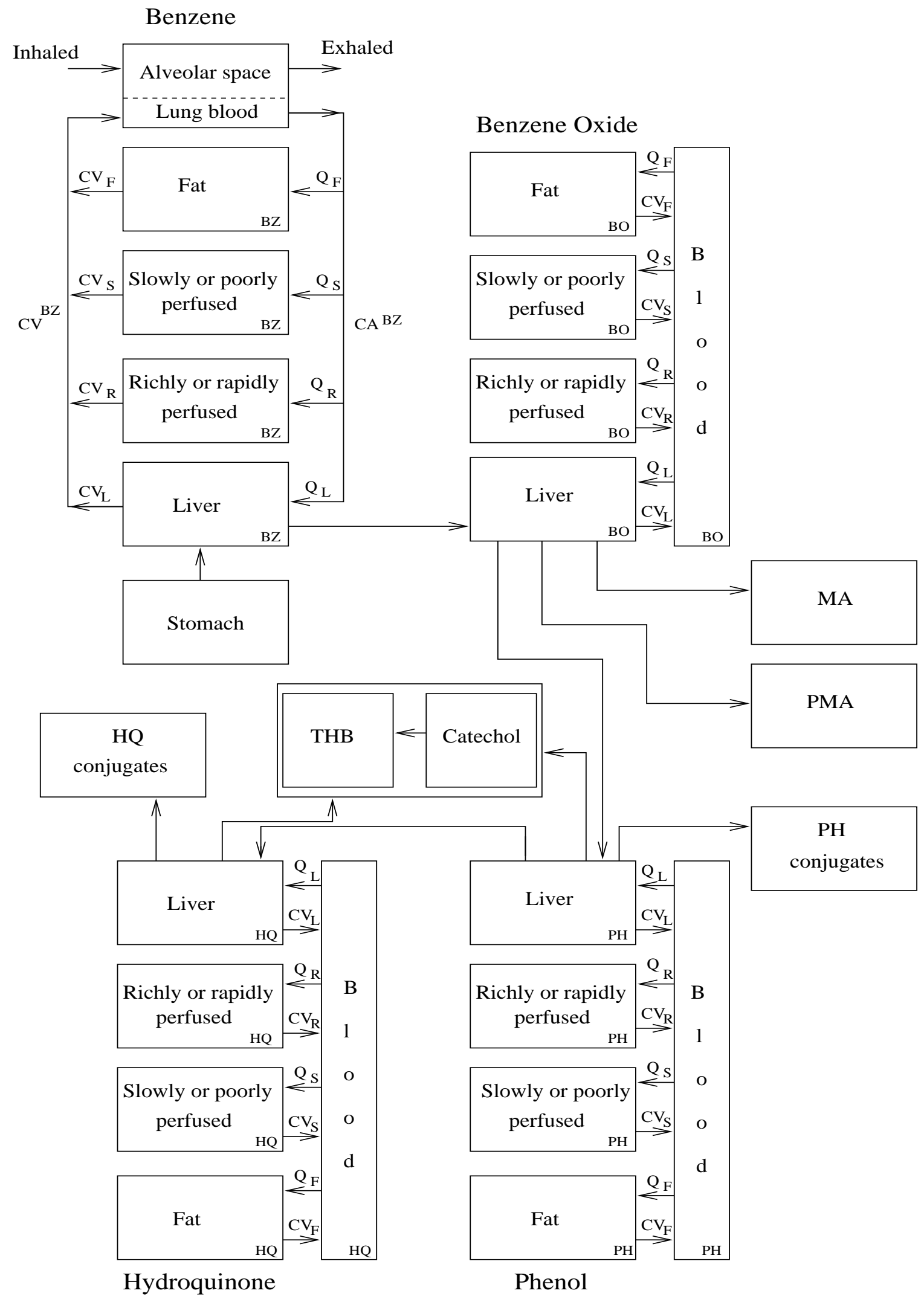

Figure 1: Schematic Representation of the Compartmental Model 


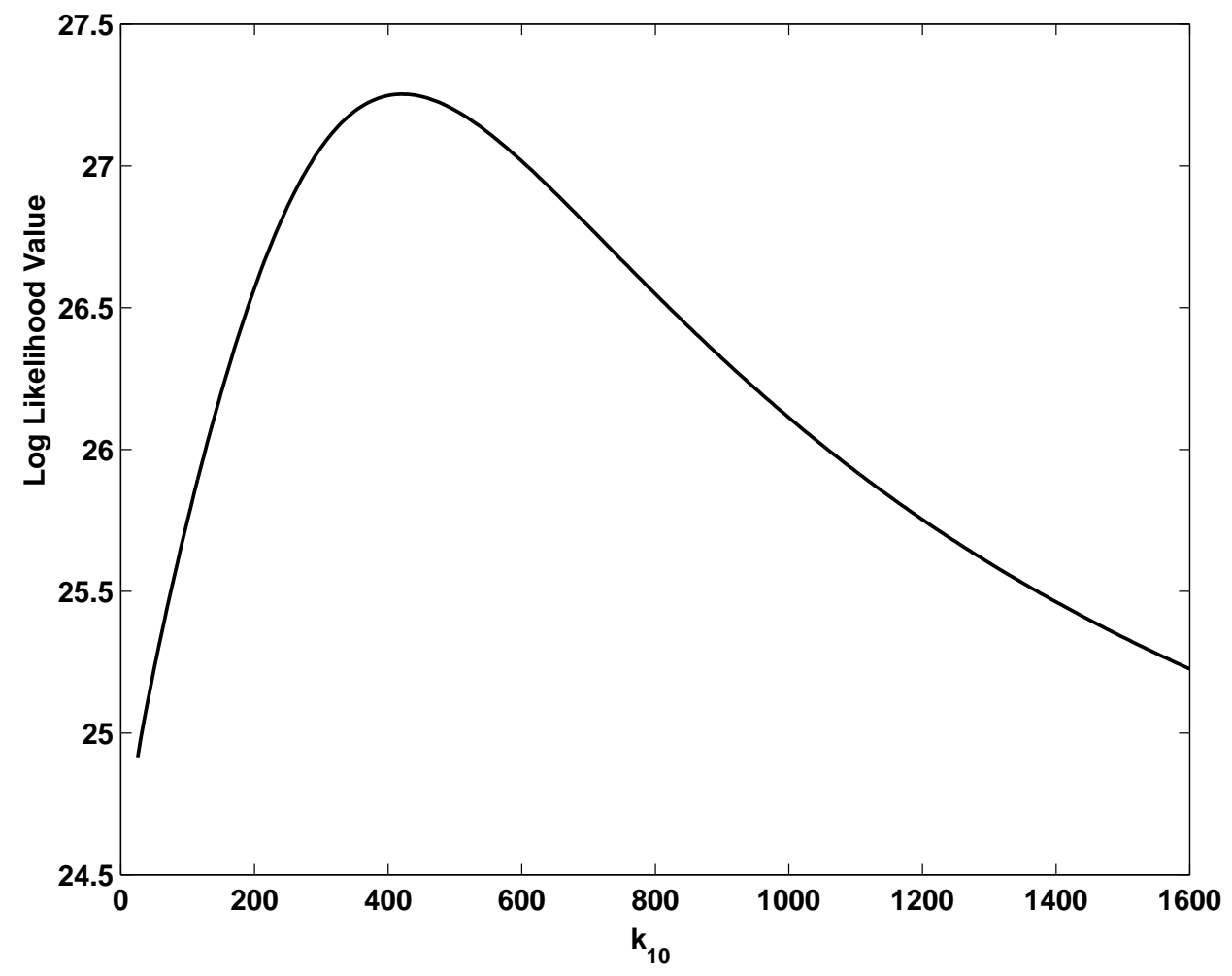

Figure 2: Maximum Likelihood Value While Varying $k_{10}$ 


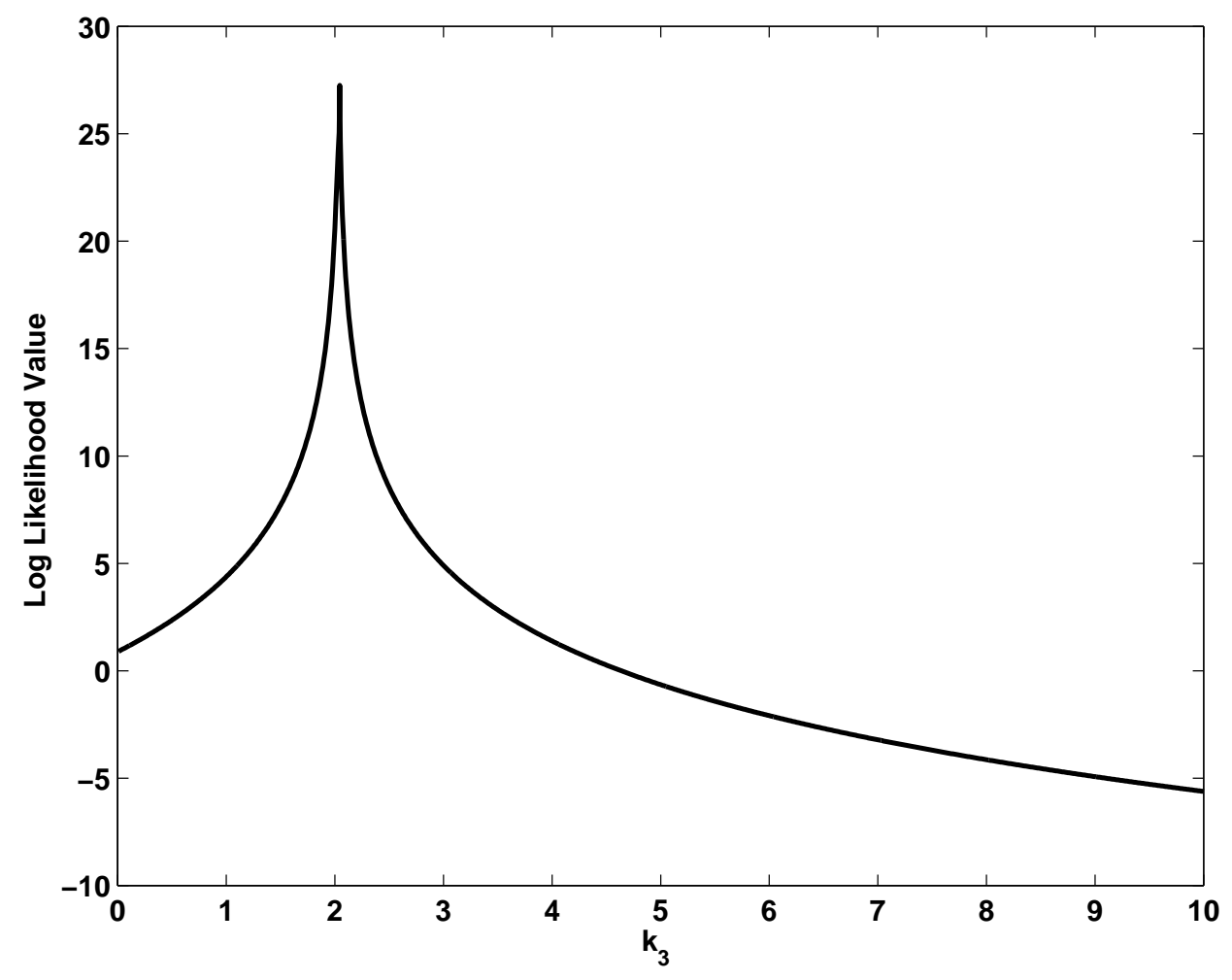

Figure 3: Maximum Likelihood Value While Varying $k_{3}$ 


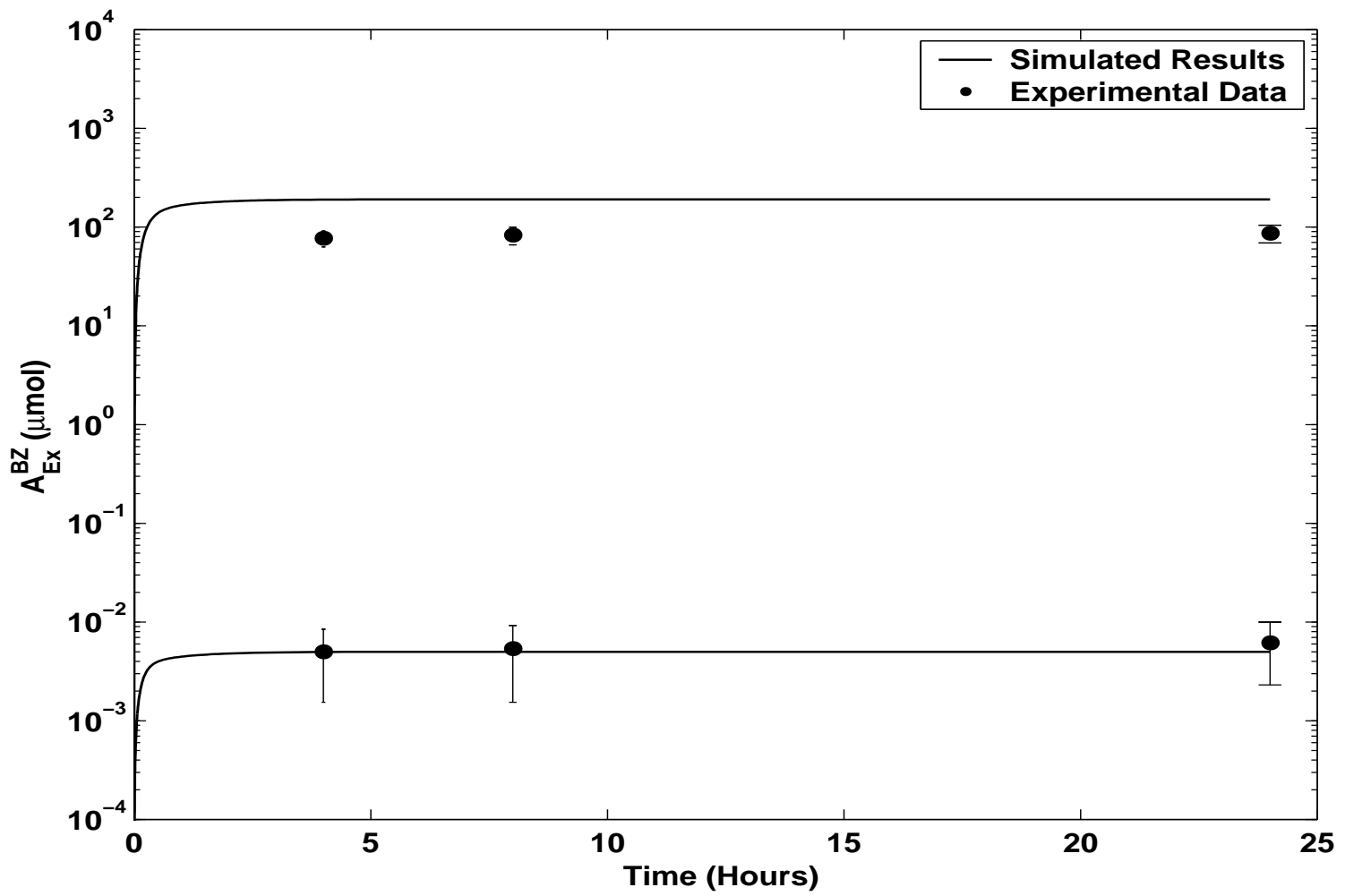

Figure 4: Time Course Data for Amount of Benzene Exhaled following Oral Dose (Mathews et al., 1998)

(The top curve corresponds to an initial dose of $0.1 \mathrm{mg} / \mathrm{kg}-\mathrm{BW}$ while the lower curve corresponds to an initial dose of $100 \mathrm{mg} / \mathrm{kg}-\mathrm{BW}$ ) 


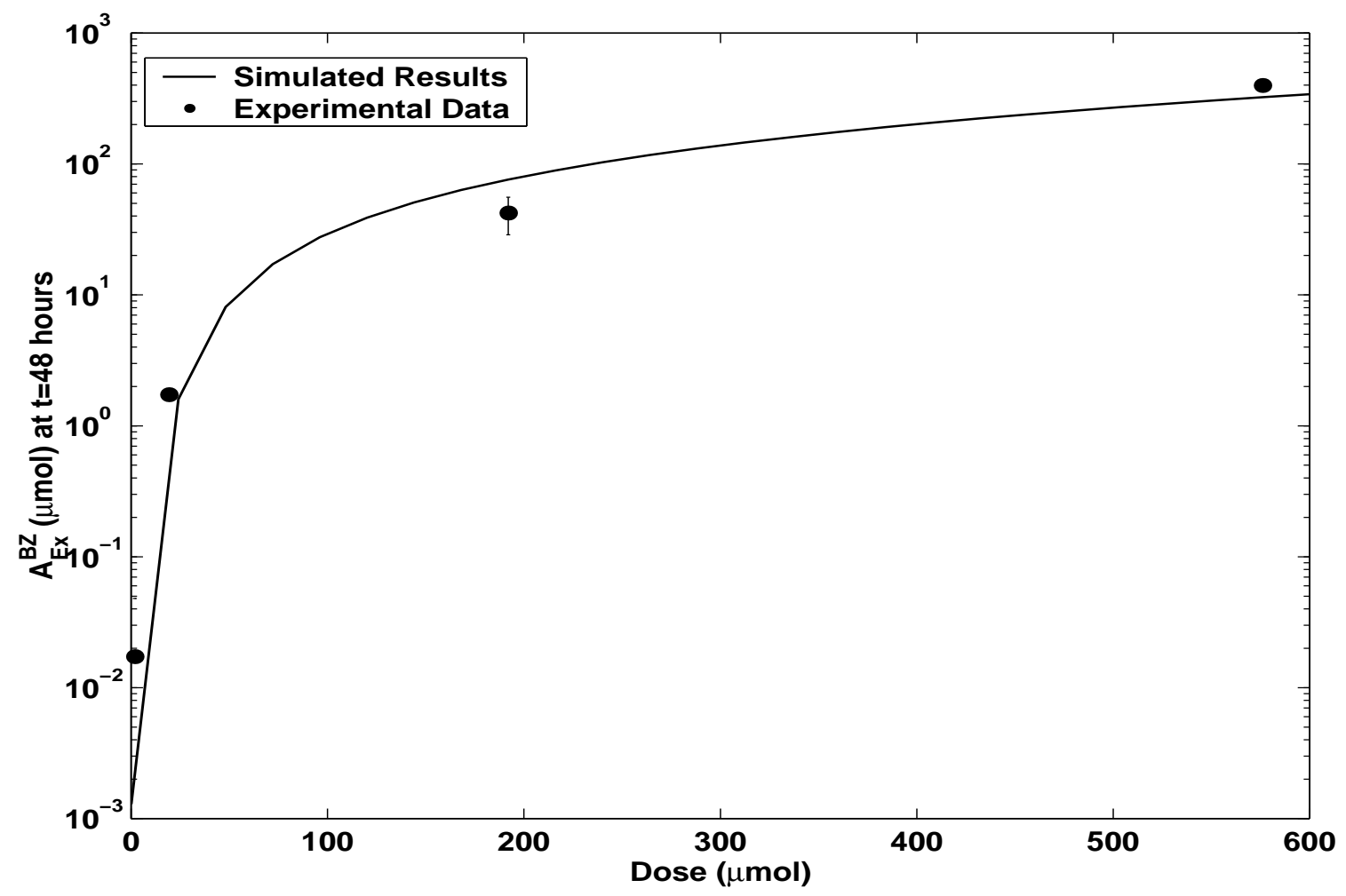

Figure 5: Amount of Benzene Exhaled at $\mathrm{t}=48$ hours following Oral Dose (Sabourin et al., 1987) 